\title{
EL ESCENARIO ACTUAL DE LA LENGUA MAPUCHE EN UN TERRITORIO. ESTUDIO DE CASO DESDE LA HISTORIA Y LA SOCIOLINGÜÚSTICA ${ }^{1}$ \\ THE CURRENT SCENARIO OF THE MAPUCHE LANGUAGE IN A TERRITORY. CASE STUDY FROM THE HISTORICAL AND SOCIOLINGUISTIC PROCESSES
}

\author{
Prof. Jaime Antimil Caniupán \\ Director Complejo Educacional Maquehue \\ Becario CONICYT - PFCHA / Magíster Nacional / 2018 - 50180168. \\ antimil.kaniupan@gmail.com \\ Dr. Aldo Olate Vinet \\ Universidad de La Frontera \\ aldo.olate@ufrontera.cl
}

\section{Resumen}

En este trabajo se analiza el escenario actual de la lengua mapuche en el marco de procesos de reconfiguración histórico-territoriales y colonialistas. Lo anterior mediante la revisión de un caso y a partir de la utilización de herramientas conceptuales de la historia y la sociología del lenguaje. Con las primeras se logra establecer la trayectoria histórica de la comunidad y con la segunda se traza el curso que tomaron las lenguas en contacto. Se concluye que los mecanismos de colonización y las dinámicas sociopolíticas establecidas en el territorio son factores determinantes tanto para la memoria histórica como para mantención y vitalidad del mapuzugun.

Palabras clave: interactividad lingüística, contacto lenguas, espacios civilizatorios, historia territorial, vitalidad lingüística.

\begin{abstract}
This paper describes the sociolinguistic relationship between Mapuzugun and Spanish in a rural bilingual community in the Araucania Region. The study explores the main communicative scenarios where the linguistic codes in contact are used, and it analyzes the current situation of the Mapuche language in the framework of the territorial-historical and colonialist reconfiguration processes. The main findings show that the mechanisms of colonization and sociopolitical dynamics established in the territory are important factors in the maintenance and vitality of Mapuzugun.

Keywords: linguistic interaction, language contact, civilizational spaces, territorial history, linguistic vitality.
\end{abstract}

Recibido: 02 de mayo de 2020

Aceptado: 10 de junio de 2020 


\section{Presentación}

La emancipación política de las colonias americanas durante los primeros años del siglo XIX no marcó el fin de los procesos coloniales, por el contrario, los nacientes Estados nacionales desplegaron relaciones de poder hegemónicas hacia los diferentes pueblos indígenas. Es lo que algunos autores han denominado colonialismo, colonialismo interno, horizonte colonial o situación colonial (Stavenhagen 1968; González 1969; Bonfil 1972; Rivera 2012; Esquit 2013), que es entendido como una estructura de dominación y explotación que pervive y se reinventa constantemente.

El colonialismo, como estructura de dominación, plasma en sus procesos las dinámicas sociales que determinan las experiencias y trayectorias de los hablantes. Los procesos sociopolíticos desarrollados a partir de este involucran, entre otros, la incorporación de instituciones, agentes y organizaciones que operan como dispositivos de control, afectando los modos de vida de las sociedades tradicionales.

El proceso de emancipación colonial trastoca la configuración sociopolítica y territorial de los pueblos, constituyéndose un nuevo estado de cosas geográfico, social y político, establecido sobre la base de relaciones de simetrías/hegemonías inter-étnicas. Uno de los componentes culturales que resiente más este proceso es el sistema de comunicación de la sociedad colonizada (su lengua), pues este, producto de la acción ejercida por las estructuras coloniales, sufre procesos de invisibilización, minorización y desplazamiento que, en muchos casos, definen la ruta hacia el cambio.

En Chile, lo anterior puede observarse en los procesos que han vivido las sociedades originarias. En particular, y de manera reciente, se observa el proceso de colonización y despojo vivido por la sociedad mapuche, el cual es, sin duda, un caso prototípico y ejemplar. El contacto inter-étnico desarrollado a partir del proceso colonizador del estado chileno marca un antes y un después para la sociedad mapuche y su lengua, pues se genera un abrupto cambio en las condiciones de interacción de la sociedad, a la que se le imponen diversos dispositivos de control (Nahuelpán et al. 2012; Nahuelpan y Antimil 2018).

La trayectoria de la sociedad y sus hablantes cambia y se condiciona al nuevo escenario colonial. Aun así esto no elimina la memoria, sino que -por el contrario- genera una memoria de la identidad acallada por la injusticia y los golpes de la modernidad que propone el proyecto estadonación chileno (Comunidad de Historia Mapuche 2012, 2015).

En este escenario, los procesos coloniales se plasman en las dinámicas comunicativas de la sociedad dominada. La interacción sociolingüística a través de la lengua (mapuzugun) comienza a verse reducida en los contextos de uso y circulación producto de la presión de los dispositivos 
asimilacionistas colonizadores y sus agentes. Se construyen idearios, imágenes y representaciones de los despojados que pueden verse reflejados en los mismos, generándose un cambio cultural que cuestiona el uso y la transmisión de su lengua.

Son estos últimos elementos los que intentamos observar en este trabajo. Queremos mostrar -de la mano de la reconstrucción histórico-territorial- la trayectoria sociolingüística del mapuzugun y el castellano en un territorio mapuche desde el momento de la "Ocupación de la Araucanía". Nuestra tesis establece que los mecanismos de colonización wigka y sus dispositivos de control generan el cambio de las condiciones de interacción sociocultural y comunicativa a partir de (a) introducción de estructuras y agentes colonizadores; (b) construcción y difusión de representaciones del colonizado y su sistema de comunicación; (c) control de los medios de producción y la mano de obra, y (d) control territorial.

Así pues, el objetivo de este trabajo es presentar un análisis histórico del proceso de desplazamiento del mapuzugun en un territorio específico, enfocándonos en el tipo de contacto desarrollado y sus consecuencias para el estado de desarrollo de la lengua.

\section{Colonialismo wigka y pueblo mapuche}

Las relaciones entre el Estado (y la sociedad chilena) con el pueblo mapuche no escapan a la noción de emancipación colonial. Varios investigadores mapuches (Marimán et al. 2006; Nahuelpán et al. 2012; Nahuelpan y Antimil 2018, 2019) afirman que la situación colonial fue instalada a partir del proceso histórico conocido como "Pacificación de la Araucanía" (1861 1883), nombre acuñado por la historiografía liberal chilena para designar la ocupación y el despojo del territorio mapuche, hasta entonces, autónomo del naciente estado nacional.

La situación colonial se edificó al alero de las ideas del liberalismo y del positivismo científico decimonónico. La oligarquía chilena creó una ideología racista para justificar la apropiación y el uso de la violencia, conformando estereotipos e imágenes del otro (Stuchlik 1974, 1985; Pinto 2003; Richards, 2016). Estos discursos, anclados en la dicotomía civilización/barbarie, proyectaron la visión de un sujeto mapuche entendido como individuo salvaje, racialmente inferior, despojable de su territorio, de sus bienes, su cuerpo y subjetividad (Nahuelpán, 2013).

El inicio del colonialismo republicano se da con el sometimiento militar y la destrucción económica del pueblo mapuche. Posteriormente, esta "máquina” fue asentando su institucionalidad, controló a los sujetos a través de dispositivos de disciplinamiento e intervino su sistema cultural, desplazando parte de sus valores y elementos culturales, que, según Fanon (1965), viven en una eterna agonía. Lo anterior, por ejemplo, puede evidenciarse en algunos planteamientos respecto del 
retroceso del mapudungun (Salas, 1992; Zúñiga, 2007; Wittig, 2009, 2011; Lagos, 2012; Gundermann et al. 2011, Wittig y Farías, 2018) y en posturas que promueven el esencialismo cultural (Fanon 1965). Estos fenómenos de desplazamiento son motivados por los mecanismos de supresión e imposición que derivan de la situación colonial (Bonfil, 1989).

Este colonialismo activó las relaciones inter-étnicas desde el condicionamiento basado en las ideologías racistas y la deshumanización del mapuche (Stuchlick, 1974, 1985, Richards, 2016). Claramente, en condiciones coloniales, el sistema de comunicación tradicional es otro elemento que también debe despojarse. Así, por ejemplo, surgen ideologías lingüísticas que vaticinan la desaparición de la lengua o el estatus inferior de esta. Sin ir más lejos, el sistema de ideologías lingüísticas que promovieron los misioneros capuchinos bávaros, Augusta (1903, 1916) y Moesbach (1930, 1962), a fines del siglo XIX y durante el XX, sobre el idioma mapuche, se enmarca en el pensamiento de las lenguas en peligro, canalizándose en el discurso sobre la desaparición de la lengua y la cultura (Olate et al., 2017). Por otro lado, en los estudios sociolingüísticos sobre el estado de la lengua, se etiqueta la situación de vitalidad de esta como la de una transformación tendiente a su desaparición y completo reemplazo por el castellano (Gundermann et al., 2011), también circulan las ideas de que el desplazamiento de la lengua es un hecho inapelable (Zúñiga, 2007) y de que el idioma sobrevive en los espacios intracomunitarios. Todos estos supuestos alimentan la ideología del mapuzugun como lengua en peligro. Es en este contexto ideológico donde los colonizadores traen un sistema de comunicación distinto que debe ser incorporado, obligatoriamente, en las dinámicas comunicativas inter-étnicas y, prontamente, intraétnicas.

Con estos elementos a la vista, no puede obviarse la condición histórica del contacto inter-étnico y, menos aún, la tensión de tradiciones socioculturales y comunicativas distintas. De qué manera se fue hilando la incorporación del castellano en el territorio mapuche, cómo fue adoptada la lengua y el sistema del colonizador por parte de la sociedad mapuche. Preguntas que pueden responderse desde la generalidad de los procesos; sin embargo, válido es exponer un caso específico que dé cuenta de las tendencias generales y particulares del proceso.

\section{Los procesos coloniales desde la sociolingüística}

Desde un enfoque que intenta ser comprensivo, Durán y Ramos describen la relación entre el mapuzugun y el castellano durante el proceso de conquista español y en el período de colonización chilena. La idea de las autoras es dar cuenta del modo en que el castellano fue incorporado por la población mapuche. 
Estos trabajos (Durán y Ramos 1986, 1987, 1988 y 1989) muestran una fuerte dinámica entre las lenguas en contacto, la que se condiciona por un marco histórico, geográfico y sociopolítico de desarrollo. El foco se fija en la incorporación del castellano por los mapuches y en la relación que establece el mapuzugun con la lengua extranjera. La perspectiva releva el proceso por el cual la lengua foránea, producto de procesos sociopolíticos y presiones sociocomunicativas, ha sido incorporada por el pueblo mapuche (Olate 2017b).

Un problema emerge al contrastar la concepción del contacto inter-étnico entre los mapuche, los chilenos y los colonos. Como sea, chilenos y colonos tienen una mirada de subestimación sobre la sociedad mapuche tradicional. En esta asimetría sociopolítica y cultural, la sociedad mapuche ha debido incorporar un sistema de comunicación perteneciente al colonizador (Durán y Ramos 1986). Además, valga señalar, que la sociedad mapuche - en esta situación- ha tenido que enfrentar y definir su identidad étnica y social, así como incorporar el sistema y código wigka, el cual fue rechazado en un momento histórico primario y adoptado voluntaria y masivamente en la actualidad (Durán y Ramos 1986). Este último tránsito histórico señalado -desde el rechazo a la adopción masiva- es la trayectoria sociolingüística que marca el derrotero de la lengua hasta nuestros días².

En un terreno más específico, el proceso histórico que ha vivido la lengua mapuche y sus hablantes es un elemento muchas veces ignorado por enfoques que hablan de la vitalidad, vigencia y mantención de la lengua. El contacto inter-étnico intenso y las repercusiones de este en los modos de vida y en los comportamientos sociales y comunicativos mapuche son cuestiones que se arrastran hasta nuestros días con un marco claro de conflictos históricos resultantes de esta colonización. Tal como sucede en estos casos, los escenarios son cambiantes y los agentes deben, constantemente, articular nuevas redes y adaptarse forzosamente. La situación lingüístico-comunicativa se direcciona hacia contextos bilingües con historicidad, los hablantes están situados en contextos políticos, económicos, demográficos tendientes a la minorización y absorción cultural.

Hay claridad al estimar que "los contactos sociopolíticos inspirados por afán de dominio y conquista, traen como consecuencia el contacto cultural obligado de los pueblos, del cual la adquisición y aprendizaje de una lengua distinta son un aspecto más” (Durán y Ramos 1986:20).

Por otro lado, enfocados en estos procesos, un componente que también se resiente se relaciona con la valoración social de la lengua subalternizada. Deben preocuparnos las razones por las que una lengua se torna valiosa o prescindible para la sociedad que la habla. La situación colonial afecta la

\footnotetext{
${ }^{2}$ La castellanización en territorio mapuche se inicia inmediatamente después de la campaña militar chilena denominada "Pacificación de la Araucanía". Durante este período se activa un proceso en dos direcciones, por un lado, la difusión, el prestigio y la estandarización de la lengua/cultura criolla en el territorio mapuche, logrando imponerse como vehículo de comunicación en las comunidades bilingües hasta nuestros días (Sepúlveda 1984); y, por otro, la estigmatización y desprestigio de la lengua/cultura mapuche. Es en esta dinámica donde ocurre la apropiación y adaptación de la lengua hegemónica por parte de los hablantes de la comunidad
} 
valoración y genera, igualmente, una trayectoria del valor social del mapuzugun que se vincula con las situaciones por la que han transitado los hablantes. Así, por ejemplo, la estigmatización social y el castigo por la práctica de la lengua son constantes históricas que alimentan el desplazamiento y la valoración negativa de la lengua.

Hasta aquí, los factores coloniales que activan el desuso de la lengua son claros: (1) construcción de un ideario (2) instituciones y agentes castellanizantes (3) valoración social del sistema comunicativo sobre la base de la precarización y el despojo.

Los procesos de cambio, mantención y desplazamiento de las lenguas deben analizarse desde el marco histórico de la formación social e histórica de pueblos, estados y comunidades. A los procesos inter-étnicos se asocia la condición sociolingüística de los idiomas subordinados y su trayectoria. Todo esto se observa en el contexto territorial, entendido como un espacio sociointeractivo, político y temporal, el cual contiene entre otros: procesos de cambio, desplazamientos, reconfiguraciones identitarias, dinámicas de resistencia en contextos de asimilación, entre otras cosas. En este escenario de la estructura colonial derivan procesos sociolingüísticos que tienen que describirse tomando en cuenta la configuración histórico-territorial de las comunidades y el condicionamiento de las lenguas a lo que llamaremos "colonialismo wigka", "colonialismo chileno" o "colonialismo republicano".

\section{El estudio}

\subsection{Objetivos de la investigación}

Los objetivos de este estudio son: (1) describir la incorporación del castellano en la comunidad de Tranantue desde un marco histórico; (2) dar cuenta de la situación actual del mapuzugun considerando la trayectoria sociolingüística de la lengua en el territorio.

\subsection{Método}

Para cumplir con estos propósitos se utilizó una metodología basada en el trabajo de fuentes orales y de archivos, con las cuales de proyecta la trayectoria de la comunidad durante el proceso de colonización chilena. Estos datos se complementan con un breve cuestionario sociolingüístico que muestra la situación actual de la lengua en el territorio. Este instrumento fue aplicado en los hogares de 20 adultos pertenecientes a la comunidad mapuche rural de Tranantue. El cuestionario indaga 
sobre la relación entre el mapuzugun y el castellano en la comunidad ${ }^{3}$ (ver anexo). A continuación se presenta el cuadro 1 con las edades aproximadas de quienes participaron en el estudio:

Cuadro 1. Participantes

\begin{tabular}{|c|c|}
\hline $\begin{array}{l}\text { Número de } \\
\text { participantes }\end{array}$ & Edades \\
\hline 2 & 75-85 años \\
\hline 4 & $60-74$ años \\
\hline 4 & $50-59$ años \\
\hline 6 & $40-49$ años \\
\hline 4 & $18-39$ años \\
\hline
\end{tabular}

A través de la recopilación oral, que sigue patrones relacionados con el género ngütramkawün, los interactuantes construyen la memoria histórica del proceso -tukulpazugun-, recordando hitos, actores y episodios, los que son elaborados a partir de juicios que rememoran aquellos eventos del pasado. El ngütramkawün es similar a una conversación, difiere de una entrevista, ya que al mantener la rigurosidad en los temas, se caracteriza como una instancia para establecer un diálogo en torno a temas definidos, en que cada interlocutor asume un rol activo que permite ir aportando y construyendo una narrativa. En determinados casos, se van contrarrestando versiones para enriquecer el relato. Esta modalidad se realizó con 16 personas, cuya edad fluctuaba entre los 40 y 85 años y de forma posterior a la aplicación del cuestionario sociolinguístico.

La lengua de aplicación de la conversación fue principalmente el castellano; sin embargo, en ciertos pasajes se alternaba con el idioma mapuche, principalmente en los participantes de mayor edad. El paso siguiente fue la transcripción de la memoria oral con el propósito de analizar los principales hitos del origen histórico-territorial de la comunidad.

Las categorías de análisis desprendidas del método de recopilación histórico-territorial se vinculan con: memoria del territorio, economía de dependencia, espacios civilizatorios, instituciones colonizadoras, transmisión generacional del sistema comunicativo. Con el cuestionario sociolingüístico, por otro lado, se da cuenta del estado actual de las lenguas (castellano y mapuzugun) en relación con los espacios civilizatorios y su transmisión generacional en el territorio.

\footnotetext{
${ }^{3}$ Este instrumento fue utilizado en el proyecto de investigación DIUFRO DI-13003 “Comunidades de habla e interacción lingüística. Un acercamiento a las dinámicas sociolingüísticas entre el mapuzugun y el castellano". Investigación desarrollada por los autores de este trabajo. Además, fue el instrumento utilizado en el estudio doctoral del segundo autor de esta contribución (Olate, 2012).
} 


\subsection{Resultados}

\section{a. Memoria del territorio}

\section{Desarticulación territorial en Ngülumapu y génesis de Tranantue como "reducción"}

En cuanto a la articulación y desestructuración del territorio de Tranantue, debemos considerar, algunas nociones relevantes para la construcción histórico-territorial. En primer lugar, la organización sociopolítica mapuche anterior a la "Pacificación" descansaba sobre unidades básicas denominadas lof - que correspondían a espacios territoriales conformados por familias emparentadas patrilinealmente, con un origen y una descendencia común (Marimán et al. 2006: 275). La máxima autoridad política era el logko; sin embargo, a partir de la ocupación del territorio mapuche, emprendida por el Estado nacional chileno desde mediados del siglo XIX, se rompió la institucionalidad político-territorial, afectando las formas de autogobierno.

Es necesario señalar, además, que la cohesión territorial de cada lof estaba regulada por una serie de elementos distintivos que, aunque compartían bases similares del sistema cultural mapuche, los diferenciaban de otros. Las formas de regulación interna, de interrelación entre lo social, natural y espiritual se denomina $a z$ mapu y resulta "de la relación de reciprocidad generada entre la población y el espacio territorial específico en el cual ésta se ha asentado" (Marimán et al. 2006: 273). El az mapu, entonces, es ciertamente análogo a la idea de identidad territorial y, como tal, tiene que ver con la interrelación dada entre ti lofche (la población) y ñi lof mapu (su territorio).

Una definición más sutil del concepto guardaría relación con el proceso de interiorización y apropiación subjetiva del territorio como objeto de representación, apego afectivo y pertenencia socioterritorial, el cual pasa a constituirse como parte de su propio sistema cultural (Giménez 1996). El az mapu está mediado por el origen familiar y territorial de las familias, küpan (descendencia) y tuwün (proveniencia) respectivamente.

Con estas precisiones, piénsese en la dramática situación dada una vez concluida la ocupación militar, momento en que el estado cercena y distribuye las tierras mapuche entre colonos nacionales y extranjeros, despojando a la sociedad tradicional de sus unidades territoriales, pues, los diferentes lof fueron reducidos por los geomensores de la Comisión Radicadora, a través de la entrega de Títulos de Merced a diversos jefes familiares (entre 1884 y 1929).

\footnotetext{
${ }^{4}$ La Comisión Radicadora de Indígenas fue una institución que funcionó entre los años 1884 hasta 1927 y fue creada por mandato de la Ley de 4 de diciembre de 1866. Estaba compuesta por tres ingenieros nombrados por el Presidente de la República, quienes debían deslindar y delimitar el terreno expropiado a los mapuche y entregárselos a las familias y grupos de familias mediante un Título de Merced. Este último era un documento que señalaba los límites de la propiedad indígena que se le reconocía a las familias, conocidas desde entonces como "reducciones". Incluía además un plano del retazo de tierra de cada grupo familiar, un censo de sus ocupantes, entre otros elementos.
} 
En cuanto al territorio foco de este estudio (Tranantue); este no es un lof sino una reducción y su constitución histórica se articula a partir de la figura del "cacique" Bartolo Levimil -nombre legal de la comunidad-, quien se presentó en Temuco el 3 de diciembre de 1896 ante la Comisión presidida por Leoncio Rivera a solicitar el Título de Merced. Al transcurrir poco más de un año, el 22 de diciembre de 1897, la entidad colonial reconocería tan solo 148 hectáreas a los cuatro troncos familiares representados por Levimil (Antimil 2016).

De acuerdo a la memoria histórica del territorio, el lofche de Tranantue tiene sus orígenes tres décadas antes de lo que consigna el Título de Merced, hablamos de 1870. El lofche tranantue se fundó tras la llegada de cuatro grupos familiares (akunche), provenientes de diferentes territorios, quienes migraron por la irrupción y presión de las fuerzas militares de la Ocupación en ese tiempo. El asentamiento se produjo gracias a la autorización del logko Tragomil Toro de Panko, quien gobernaba este territorio en calidad de anümche (originario del territorio), quedando las familias políticamente sujetas a su influencia (Antimil 2016).

Estas cuatro familias se integraron a los espacios de cohesión socioterritorial, separándose "legalmente" a partir de la radicación y con la entrega de Títulos de Merced para las reducciones Toro Llanquimil y Domingo Llanquimil de Panko, y Bartolo Levimil de Tranantue. Este hecho fractura la institucionalidad mapuche previa.

Algunas prácticas colectivas mantuvieron unidas a las familias; sin embargo, esto duró solo hasta la primera parte del siglo XX. La reducción de Tranantue se separó de la de Panko, lo que produjo que varias familias de la primera se restaran de participar del Ngillatun conjunto que celebraban. Otro factor que afectó la cohesión interna del lofche se vincula con las diferencias de küpan y tuwün entre las familias, lo que condicionó las relaciones de la comunidad tanto con el mundo natural y con el mundo espiritual (az).

La irrupción del colonialismo chileno desestabilizó la identidad territorial que estaba gestándose y suspendió el proceso de interiorización y apropiación del lofche. Con esto, la consolidación del az mари no se logró y, al momento de la Ocupación, se generó una cohesión interna superficial que fue reforzada, a su vez, por la instalación de colonos en las cercanías y el empobrecimiento de la comunidad. Ya, con este escenario, el lofche tuvo que articularse socioeconómicamente y la configuración del az mapu debió establecerse con estos términos. 


\section{b. Economía de la dependencia}

\section{Subsunción de la economía mapuche y "creación de la dependencia"}

La consolidación de Temuco como capital regional implicó la demanda de bienes producidos en las comunidades (leña, tejidos, ganadería menor y hortalizas), lo que significó una rearticulación económica e inserción de las comunidades al circuito económico emergente; sin embargo, las relaciones de intercambio fueron desiguales, conduciendo a un progresivo empobrecimiento y descapitalización de las "reducciones" (Alonqueo 1985).

Este proceso general también se replicó en Tranantue, pues, si bien los primeros años después de la ocupación fueron momentos de relativa convivencia entre colonos y miembros de la comunidad, esta quedó relegada producto de la desarticulación del sistema económico mapuche, que fue subsumido, re-definido e insertado como economía minorizada al circuito emergente (Nahuelpan 2012).

Por lo anterior, el "relativo equilibrio económico" y reconocimiento mutuo entre los mapuche de Tranantue y sus vecinos colonos a fines del siglo XIX se transformó en una asimetría acentuada en las primeras décadas de la nueva centuria, momento en que familias mapuche empobrecidas se vieron forzadas a establecer relaciones de dependencia con la economía colonial local y regional, convirtiéndose en mano de obra (por ejemplo, peones, "mocitos", inquilinos, medieros en los fundos y/o hijuelas y servidumbre doméstica en la ciudad de Temuco). La racialización de la mano de obra se convirtió en un elemento estructural visible de la situación colonial y un claro dispositivo de control comunicativo y de desplazamiento lingüístico (Nahuelpán 2012; Antileo 2015).

Otro elemento que se activó a partir de estos procesos de pauperización y dependencia económica fue la migración, que tuvo su razón en las condiciones materiales que las comunidades adoptaron producto de la disolución de la base económica, la reducción territorial y el agotamiento de los suelos (Antileo 2012). En el caso de Tranantue, los flujos migratorios de miembros de la comunidad son hacia Argentina, en primera instancia, y, posteriormente, a ciudades como Santiago, Valparaíso y Temuco.

La generación de una economía de dependencia durante la situación colonial produjo el empobrecimiento de la sociedad mapuche, lo que implicó su dominio, explotación y dependencia. A partir de la década de 1930, las relaciones establecidas entre la sociedad mapuche y el poder económico chileno-colonial sufren un cambio que acelera el control social, la invisibilización y la subalternización, lo que se traduce en la emergencia de la peonización, la servidumbre doméstica, 
los intercambios desiguales y las migraciones forzadas, consolidándose de esta manera la dependencia económica y la subordinación a las condiciones del colonizador

Desde la lectura sociolingüística, los procesos económicos, la conversión de la mano de obra y el empobrecimiento de la sociedad mapuche permiten la incorporación de estructuras y agentes que difunden el castellano y lo imponen como la lengua "oficial" con la que se accede a mínimos beneficios para sobrellevar el despojo.

\section{c. Instituciones, contextos y transmisión de la lengua. Difusión de la lengua y transmisión post-ocupación}

"Espacios civilizatorios" como espacios de control colonial y lingüístico

Le empresa moderna trae consigo diversos dispositivos que buscan el control social y la asimilación. La idea de lo civilizado y lo bárbaro se toma el proyecto colonizador con lo que se traza la tarea de "civilizar al indio" y "chilenizarlo". Para lograr este propósito se introdujeron espacios e instituciones donde se disciplinaba a los colonizados (como ciudadanos de segunda clase) y se los formaba con hábitos y valores que decantarían en un cambio cultural (Nahuelpán 2012).

En esta dinámica es que surgen los “espacios civilizatorios”, entendidos como conjuntos de dispositivos desplegados por la sociedad colonial para generar una transformación cultural, ideológica y social en las sociedades (indígenas) sometidas a su régimen (Nahuelpán 2012). En el contexto mapuche, estos espacios corresponden, entre otros, a los fundos, hijuelas, casas patronales, hospitales, misiones, escuelas, la ciudad y las instituciones estatales. Unidades que operan como espacios de disciplinamiento y de producción y reproducción ideológica. Allí, por medio de discursos y acciones cotidianas, se refuerzan las asimetrías y la subalternización a la que han sido expuestas las generaciones mapuche, estructurándose de este modo, en la vida cotidiana, el racismo y la violencia que marcan el devenir histórico de la sociedad mapuche (Nahuelpán 2012; Nahuelpan y Antimil 2018).

Desde una mirada sociolingüística, los espacios civilizatorios se vinculan con los ámbitos de uso de las lenguas, ya que representan instituciones socioculturales adscritas a modelos que emanan de sociedades diferentes. Lo relevante aquí es que hay espacios civilizatorios donde el ámbito de uso se anida en la sociedad dominante (escuela, iglesia), lo que puede llevar a la asimilación identitaria, y hay otros que son parte de la sociedad subalternizada (machitun, ngillatun) que operan como espacios de resistencia cultural. 
En Tranantue, los “espacios civilizatorios” operaron tempranamente. En fundos e hijuelas se advierte una incorporación temprana de miembros de la comunidad por medio de relaciones laborales semiserviles, esto ocurre, principalmente, entre 1930 y 1980 . Testimonio de este hecho se observa en el ngütramkan entregado por A. Antimil, donde señala su labor inicial como "mocito", hacia mediados de la década de 1930, que luego se transforma en peón, para continuar como mediero e inquilino. Su ngütramkan muestra algunas claves del proceso. Sobre su estadía como "mocito" señalaba:

Era buena persona el viejo ese. Todas eran buena persona, eran gente buena. Por eso que nosotro' también fuimo' bueno trabajadore', no borracho, no andar por ahí peleando, ni'una cosa, es lo que decía él. Él nos crio como hijos a nosotros. Había un hombre ahí, Ramón Ulloga, ese me estaba enseñando (...) También estaba bien ahí. El mismo don Santiago le decía "tení que enseñarle al niño". Niño me decía. (A. Antimil 2012).

El patrón de fundo fue el principal agente de disciplinamiento, transformándose en un referente paternal y agente educativo que contribuyó a la conformación del az che (identidad personal) y a su wigkawün (chilenización). Durante este periodo, la representación del mapuche por parte de la sociedad chilena se caracterizó por el paternalismo y la "responsabilidad del hombre blanco" de "llevar al mapuche a la civilización" (Stuchlik 1985).

Junto con las casas patronales de servidumbre doméstica, las ciudades, con el ciclo migratorio, se constituyeron en "espacios civilizatorios" donde hombres y mujeres enfrentaron la discriminación y racismo, provocando el desapego de elementos culturales propios y la adopción de formas "civilizadas" como estrategia para disminuir los efectos de la sociedad colonial o como proceso de internalización del colonialismo (Memmi 1971; Fanon 1973).

Uno de los espacios civilizatorios prototípicos fue la escuela, allí se impulsó el proceso de “chilenización" y "civilización” de la población mapuche (Canales 1998). En la comunidad de Tranantue, la escuela tiene cuatro momentos históricos: (1) hasta 1930 con la presencia de una escuela fiscal en el territorio de Collimallin, a 6 kilómetros de Tranantue; (2) de 1930 a 1945 con una "escuela itinerante" en la propia comunidad, donde las profesoras a cargo arrendaban dependencias de los mismos mapuche; (3) de 1945 a 1977 con escuelas en fundos e hijuelas de los colonos y; (4) de 1978 hasta la actualidad con una escuela instalada a un kilómetro en la vecina comunidad de Panko.

Para los procesos de desplazamiento lingüístico, la escolarización es clave, pues por medio de este dispositivo se introduce la lengua del colonizador y en su espacio se modifican las actitudes e ideologías hacia la lengua colonizada. Así las cosas, el momento 1 (Collimallin) fue la instancia 
donde se introdujo el castellano y, junto con ello, se prohibió el uso del mapuzugun a través del uso recursos punitivos y la violencia psicológica (Alonqueo 1985; Canales 1998; Quintriqueo 2010).

El período de la escuela itinerante en la comunidad escolarizó fuertemente a esa generación de niños mapuche, lo que queda en evidencia en los documentos del Censo Indígena de 1965 (ver tabla 1).

Tabla 1: Escolarización de Tranantue según Censo Indígena de 1965

\begin{tabular}{|l|l|l|}
\hline Variables & $\begin{array}{l}\text { Escolarización según Censo } \\
\text { Indígena, 1965. }\end{array}$ \\
\hline \multirow{4}{*}{ Escolaridad } & Escolarizados & 25 personas \\
\cline { 2 - 3 } & Analfabetos & 6 personas \\
\cline { 2 - 3 } & Escolaridad Máxima & $5^{\circ}$ Primaria \\
\cline { 2 - 3 } & Escolaridad Promedio & $3^{\circ}$ Primaria \\
\hline Total entrevistados & 31 \\
\hline
\end{tabular}

Fuente: Elaboración propia a partir de los resultados del Censo Indígena practicados en la comunidad el 11 de marzo de 1965. Archivo General de Asuntos Indígenas. Carpeta administrativa 448. Censo Indígena comunidad Bartolo Levimil s/fs. AGAI-CONADI. Temuco.

Puede observarse que esta generación tuvo una población altamente escolarizada (81\%), lo que provocó que casi toda ella incorporara el castellano e iniciara un proceso de quiebre de la transmisión del mapuzugun. La razón de este comportamiento, nuevamente, puede deberse a la contención de la violencia colonial o por asimilación de los valores culturales de la sociedad hegemónica.

La cuarta generación igualmente se sometió a la férrea disciplina escolar y su totalidad asistió a las aulas de los fundos e hijuelas pertenecientes a los colonos. Se destacan varios establecimientos: Escuela Particular No 229 "Deille"; Escuela mixta No 60 "Rucamanque" y Escuela Fiscal “Copihue”. Al respecto, el ngütramkan de la papay J. Painevilo da cuenta de un importante elemento relacionado con la supresión lingüística de sus compañeras y compañeros de Tranantue que sabían hablar mapuzugun:

La mayoría no hablaban si en mapuzugun. No hablaban. Eramo', vario mapuche, pero nunca intentaron de hablar la dema' sobre to'o, la A. H la hija de A. H. nunca intentaron, igual J.L.H. To'o eso tuvimo' en la escuela ahí pu. Nunca intentaron, siempre hablaban en castellano no más. La señora de don R. M. to'o eso 'tuvimo' en la escuela. Y todo' sabían hablar mapuzugun, pero nunca intentaron hablar así pu. (J. Painevilo, 2014)

En el contexto familiar, estos niños habían recibido el mapuzugun de sus abuelos y abuelas, quienes eran hablantes competentes de la lengua. Los niños nacidos durante la década de 1960 no tuvieron la misma suerte, pues a ellos no se les entregó el sistema comunicativo mapuche, pues los 
futache (abuelos) fueron falleciendo. Los padres de esta generación, escolarizados e incorporados a la economía de dependencia, desvalorizaron su origen lingüístico-cultural y restringieron la transmisión de la lengua. Claramente, este comportamiento se origina a partir del funcionamiento de los dispositivos coloniales y la violencia que estos ejercieron.

Desde una mirada funcional, el uso de la lengua mapuche no era aceptado en los espacios coloniales, por lo cual se relega su uso a espacios íntimos y ceremoniales específicos. Como bien se sabe, el castellano se convierte en el instrumento de comunicación de la comunidad en casi todos los espacios de interacción social.

En la comunidad de Tranantue, al parecer, triunfó el proceso de internalización del colonialismo a partir de los espacios civilizatorios y la economía de la dependencia. Así las cosas, el cambio lingüístico se concreta junto con el desplazamiento de otros elementos culturales vinculados con la extinción de estructuras y agentes de la sociedad mapuche de la comunidad, lo que permite la promoción de aspectos culturales wigka.

En el desarrollo histórico descrito, observamos que los espacios civilizatorios fueron estructuras de disciplinamiento y fuente de la transformación social que aceleraron la internalización (forzada) del colonialismo, modificando los esquemas simbólicos y culturales y reproduciendo, por imposición y supresión, el modelo colonial (Bonfil 1989).

Por otro lado, desde una perspectiva que podríamos llamar "sociolingüística de la colonización", la difusión de los espacios civilizatorios (un concepto más complejo y rico que el de ámbito de uso) y el comportamiento que se reprodujo allí contra la lengua son claves para la emergencia de una actitud de estigmatización hacia el código y el quiebre de su transmisión. Si a esto se suman los mecanismos de protección como la invisibilización étnica y la asimilación colonial, entonces, la promoción del sistema comunicativo mapuche se debilita.

\section{d. Los efectos de las relaciones sociolingüísticas coloniales: el estado actual del mapuzugun en}

\section{Tranantue}

\section{El uso actual de las lenguas en los "espacios civilizatorios"}

Si bien la noción de espacio civilizatorio es más compleja que la de ámbito de uso sociolingüístico, vale la pena tomar ciertos elementos de esta última para generar una descripción más rica de la relación sociolingüística colonial. Esto en el entendido de que los ámbitos de uso se relacionan con los contextos institucionales y culturales que hay en la sociedad (en general) y en la comunidad (en específico); estos ámbitos pueden ser interpretados como dispositivos de control introducidos en una situación colonial, podemos considerarlos espacios civilizatorios, pues contienen 
elementos coloniales de dominación y disciplinamiento, reproductores de comportamientos y actitudes de estigmatización y violencia simbólica.

Comprendidos así, los ámbitos de uso muestran las tendencias de los hablantes en el uso de los códigos comunicativos en los espacios civilizatorios. El establecimiento de un ámbito de uso permite conocer la dinámica sociocultural de las comunidades estudiadas y, también, diferenciar los espacios civilizatorios de los espacios de resistencia cultural.

Ante la pregunta ¿Con qué frecuencia habla usted mapudungun en los "lugares" que se mencionan a continuación?": (1) Machitun; (2) Ngillatun/Wetripantu; (3) Siembra/Cosecha; (4) Palin; (5) Velorio; (6) Reuniones de la comunidad; (7) Torneos deportivos; (8) Fiestas familiares; (9) Actos escolares; (10) Reuniones de apoderados, pueden establecerse ámbitos congruentes con espacios de mantención cultural y otros vinculados a espacios civilizatorios.

Precisamente, frente a esta interrogante, se evidenció que en los ámbitos de mantención cultural (actividades rituales mapuche) hay un alto porcentaje de entrevistados que no respondió la frecuencia de uso de la lengua en el espacio ceremonial "machitún”, lo que puede explicarse por la desestructuración de la sociedad tradicional, hecho que (1) modifica la percepción de salud/enfermedad desde una concepción tradicional (mapuche) a otra occidental; (2) permite el arribo de credos protestantes que cuestionan la figura de machi. Los otros espacios de mantención cultural, igualmente, ven mermados el uso del mapuzugun, pues se trata de ceremonias de frecuencia anual o bi-anual. En el gráfico 1 se observan las tendencias de uso del mapuzugun en los espacios de la comunidad.

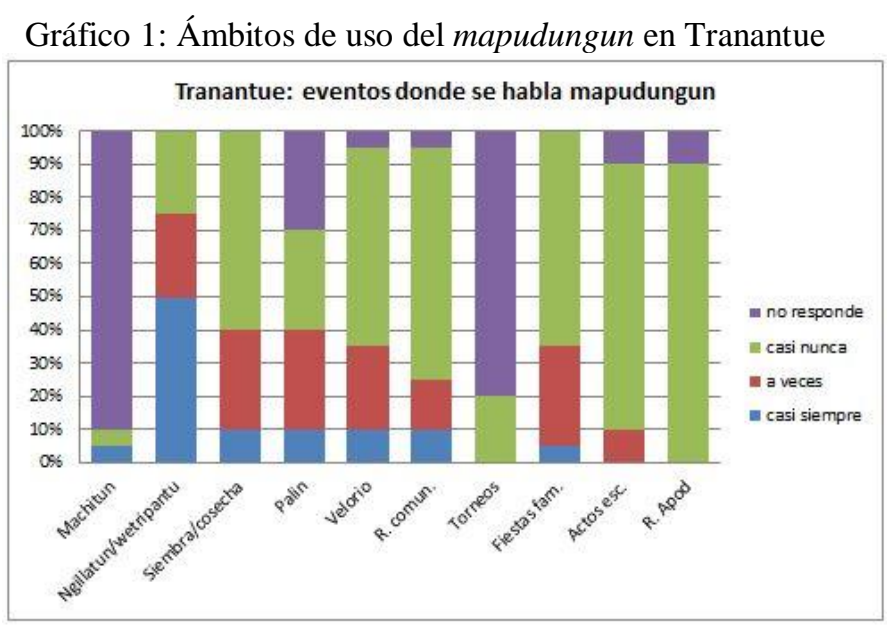

Como se ha detallado en el análisis histórico, en la actualidad, el proceso de aculturación y la colonización sociolingüística siguen su curso de manera inapelable en esta comunidad, estableciéndose un claro proceso de desuso de la lengua en espacios de mantención cultural y, obviamente, en los espacios civilizatorios. Las causas ya fueron advertidas en la sección anterior. Es 
interesante contrastar la tendencia del gráfico 1 con lo presentado en el gráfico 2, pues se observa que el castellano (azul en gráfico 2) cubre casi todos los ámbitos propuestos.

Gráfico 2: Ámbitos de uso del castellano en Tranantue

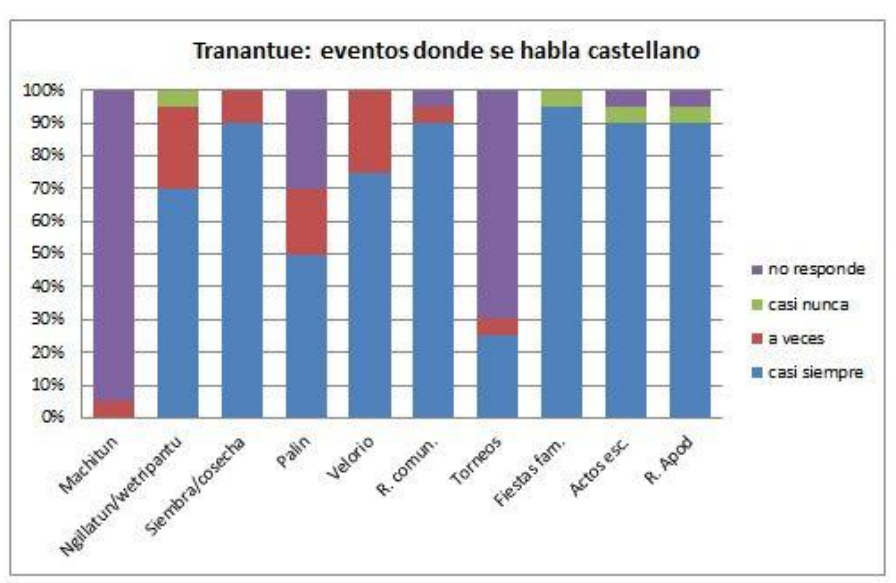

El desplazamiento de la lengua se evidencia al ver las respuestas dadas respecto de qué lengua fue la primera que se aprendió en la comunidad. El 75\% de los participantes respondió que la primera lengua fue el castellano, solo el $25 \%$ habla la lengua como L1.

\section{La transmisión generacional de la lengua en Tranantue}

La mantención o el desplazamiento se definen, entre otras cosas, por la transmisión de la lengua. El proceso toma lugar en el núcleo familiar y en los circuitos comunicativos de la comunidad, tiene que ver con los patrones de uso y el traspaso de los códigos entre las generaciones integrantes de una comunidad.

La transmisión tiene direccionalidad, es decir, la interactuación comunicativa que protagonizan los miembros de la comunidad en los eventos de habla implica la concurrencia -en estos espacios- de agentes generacionales que se comunican, direccionando el código entre ellos. En los casos de colonización, las lenguas alternan en su uso entre los agentes generacionales por lo que su transmisión puede restringirse hacia ciertas generaciones (niños y jóvenes), agudizando el desplazamiento de la lengua (Thomason y Kaufman 1988), cuestión que también implica el problema de la planificación lingüística familiar intergeneracional.

La transmisión intergeneracional, por tanto, influye en el cambio lingüístico, también ocupa un lugar central en los procesos de transmisión cultural y de reconocimiento identitario (Ghio y Fernández 2008). Cabe recordar que existe una construcción de realidad que es inseparable del entorno donde se adquiere el lenguaje. Por ello, los procesos de colonización activan situaciones dramáticas que transforman totalmente las realidades pre-existentes.

En este contexto, la situación actual de la lengua en la comunidad de Tranantue, en relación con este factor, es poco alentadora, pues la generación que habla alternadamente las lenguas, 
aunque con más tendencia al uso del castellano, es la de los ancianos (35\% mapuzugun), los adultos hacen cambio de código (55\% alternan). Niños y jóvenes no hablan mapuzugun (95\% castellano). Los datos expuestos corroboran lo señalado por Croese (1983), Hernández y Ramos (1983); Contreras (1999); Zúñiga (2007); Gundermann et al. (2009); Olate et al. (2013), Zúñiga y Olate (2017), entre otros. La representación de la tendencia puede observarse en el gráfico 3

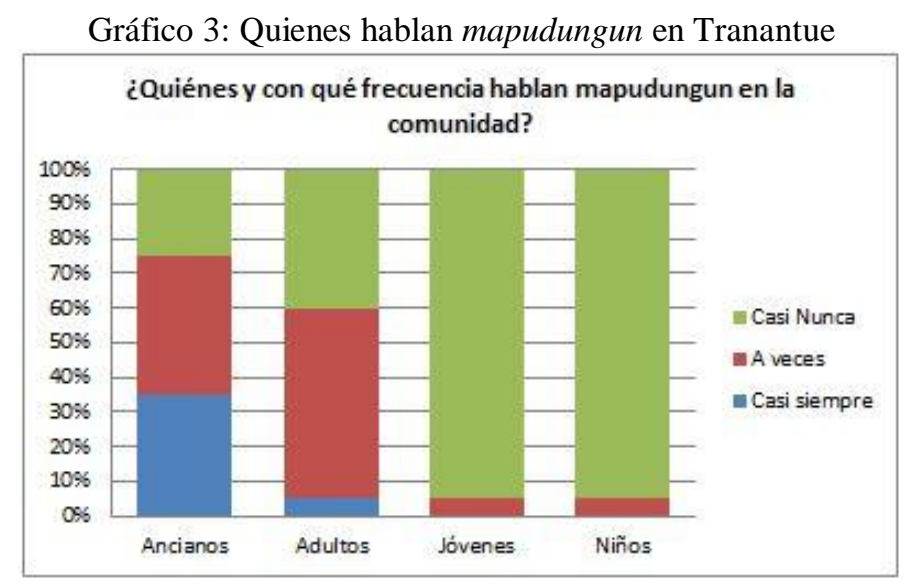

La transmisión en el núcleo familiar también es poco alentadora, pues la interacción entre los miembros usando el mapuzugun es poco frecuente. Así, con los padres no se practica la lengua, en el contexto matrimonial (entre padres) tampoco. La comunicación con los hijos sigue la misma tendencia (al respecto, obsérvese el gráfico 4).

La comunicación en la lengua fuera del círculo familiar íntimo mantiene la tendencia. Con estos datos se explicita el hecho de que los padres no les hablan mapuzugun a sus hijos, generándose el quiebre de la transmisión en contextos íntimos y públicos.

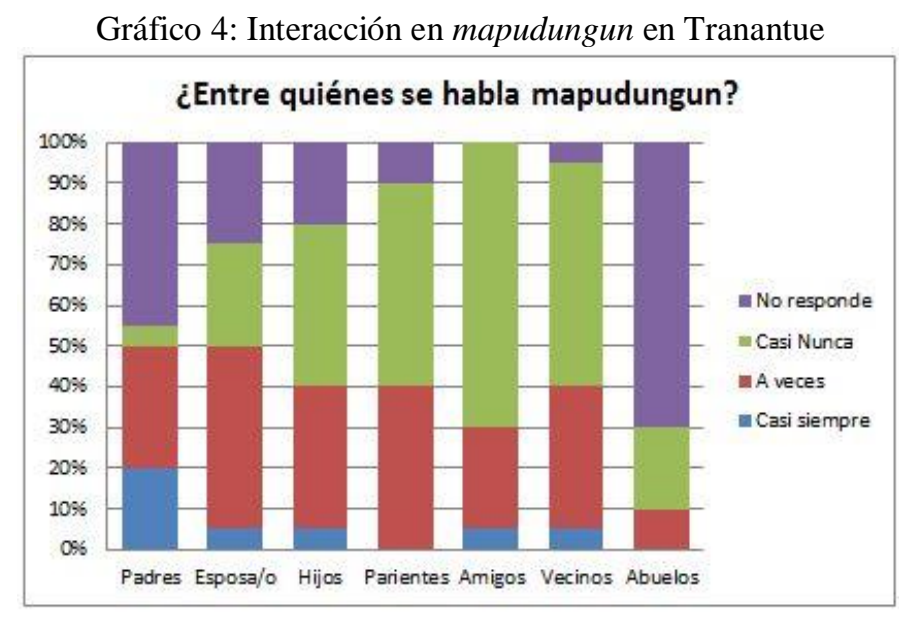

La interacción entre generaciones tiende también a la retracción de la lengua. Así, entre ancianos se habla mapuzugun, pero se alterna mucho más, cuestión que prima entre los adultos, 
aunque aquí la tendencia predominante es hacia el uso del castellano. Qué decir de la interacción entre jóvenes y niños. Aquí el código comunicativo que prevalece indiscutiblemente es el castellano. En el gráfico 5 se observan las tendencias que responden a la interrogante, ¿entre quienes y con qué frecuencia hablan mapuzugun?

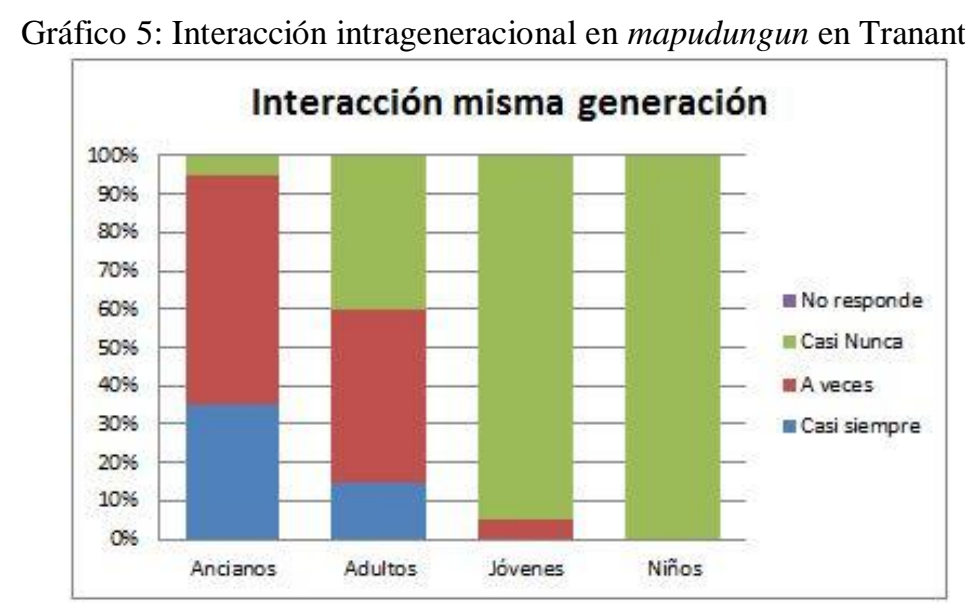

En la interacción entre generaciones, predomina el uso del castellano por sobre la alternancia y la lengua mapuche, cuestión que se evidencia en el gráfico 6.

En la actualidad, está claro, el éxito de los espacios de civilizatorios sigue marcando la trayectoria de la lengua y su retracción. Se observa que no hay neohablantes ni mayores esfuerzos por parte de la comunidad de mantener la lengua.

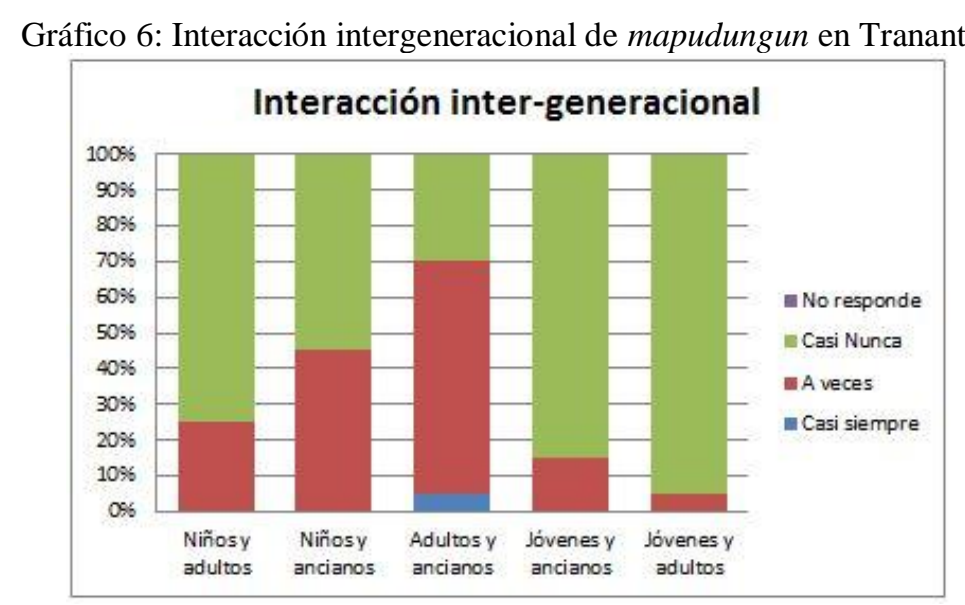

En el contexto general de este trabajo, el desplazamiento de la lengua mapuche y los cambios culturales dados en las sociedades colonizadas -expuestas a los dispositivos colonialesnaturalizan la desigualdad, la explotación y las jerarquías socio-raciales, reproduciendo valores, pautas, normas y hábitos de la sociedad hegemónica. En esta dinámica, el componente sociolingüístico se integra y se acopla a las naturalizaciones y representaciones señaladas. 


\section{Conclusiones}

A partir del análisis histórico territorial, nuestra propuesta intentó trazar la trayectoria del mapuzugun en la comunidad de Tranantue hasta nuestros días. La reconstrucción históricoterritorial nos permitió fijar los elementos más relevantes que desencadenaron el desplazamiento de la lengua en dicha comunidad. Por otro lado, los datos sociolingüísticos nos entregan un panorama del estado actual del proceso en lo vinculado a las lenguas en la comunidad. El escenario, por cierto, no es nada alentador.

El proceso de colonización condicionó la mantención de la lengua y aceleró la incorporación del castellano. El componente sociolingüístico aparece en esta cadena por defecto, pues, claramente, los factores socioestructurales (políticos, económicos, demográficos, simbólicos) son los gatillantes del proceso de cambio lingüístico.

En este estudio se explicita la influencia que han tenido estos factores socioestructurales en el desplazamiento de la lengua. En primer lugar, la precarización y la economía de la dependencia son aspectos ineludibles para comprender la migración de los hablantes hacia el castellano. En segundo lugar, la incorporación de espacios civilizatorios como herramientas de control y disciplina transforman tanto los circuitos comunicativos de la comunidad como los comportamientos de los hablantes, sus ideologías y representaciones sobre el código propio y el del colonizador.

El establecimiento del marco histórico nos permitió ver, con cierta claridad, el devenir sociolingüístico del mapuzugun. La reconstrucción de las dinámicas territoriales, desde el horizonte colonialista, nos deja mirar los procesos sociolingüísticos de otra manera, sujetos a los contextos históricos internos de la comunidad, que son sensibles al proceso general producido en la Araucanía. Con esto se muestra la importancia de las trayectorias históricas de las comunidades y sus miembros.

Finalmente, el colonialismo es una estructura de dominación que ha tenido estrategias y mecanismos explícitos e implícitos en su despliegue, es un sistema que se reinventa constantemente, por ende, hacer lecturas críticas de los actores y elementos que conforman su andamiaje en un contexto histórico específico permite develar sus reformulaciones, advertir sus posibles efectos y formas de resistencia. 
${ }^{1}$ Realizado gracias al apoyo del proyecto FONDECYT 1180071.

Agradecimientos: A la comunidad de Tranantue. Que esta reflexión colabore a revertir la progresiva agonía de nuestra lengua y a desmontar la situación colonial.

\section{Referencias}

Alonqueo, Martín. Mapuche, ayer-hoy. Padre Las Casas: Imprenta y Editorial San Francisco 1985.

Antileo, Enrique. "Migración mapuche y continuidad colonial". En Ta iñ fijke xipa rakizuameluwün. Historia, colonialismo y resistencia desde el país Mapuche, editado por Comunidad de Historia Mapuche. Temuco: Ediciones Comunidad de Historia Mapuche, 2012. 193214.

Antileo, Enrique. "Trabajo racializado. Una reflexión a partir de datos de población indígena y testimonios de la migración y residencia mapuche en Santiago de Chile", Meridional, Revista de Estudios Latinoamericanos 4 (2015): 71-96.

Antimil, Jaime. Panko ka Tranantue Mapu ñi Kuifike Zungu. Historia de las comunidades de Panko y Tranantúe desde la segunda mitad del siglo XIX hasta 1950. Tesis para optar al grado de Licenciado en Educación. Temuco: Universidad de La Frontera, 2012.

Antimil. Jaime. "Panko, Wenumalal ka Trananatue mapu ñi tukulpazungun. Reconstrucción del territorio ancestral de comunidades Mapuche a través del rescate del Kuifyke zungu". En, Pedro Canales Tapia, Enrique Antileo Baeza, Jaime Antimil Caniupán y otros. Zuamgenolu. Pueblo Mapuche en Contexto de Estado Nacional Chileno. Santiago: Ediciones USACH, (2016): 155-179.

Augusta, Félix. “Gramática Araucana”. Valdivia: J. Lampert, 1903.

1916.

.Diccionario Araucano-español y Español-araucano". Santiago: Imprenta Universitaria

Comunidad de Historia Mapuche. Ta ĩ̃ fijke xipa rakizuameluwün. Historia, colonialismo y resistencia desde el país Mapuche. Temuco: Ediciones Comunidad de Historia Mapuche, 2012.

.Awükan ka kuxankan zugu wajmapu mew: Violencias coloniales en Wajmapu. Temuco: Ediciones Comunidad de Historia Mapuche, 2015.

Bonfil, Guillermo. "El Concepto de Indio en América: Una Categoría de la Situación Colonial”, Anales de Antropología (1972): 105-124.

."La Teoría del Control Cultural en el estudio de procesos étnicos”, Estudios sobre las Culturas Contemporáneas 12 (1991[1989]): 165-204.

Canales, Pedro. "Peyepeyen. Escuelas chilenas en contextos mapuche", Revista Última Década 9. (1998): 1-15.

Contreras, Constantino. "El castellano hablado por mapuches. Rasgos del nivel morfosintáctico", Estudios Filológicos 34 (1999): 83-98.

Croese, Robert. "Algunos resultados de un trabajo de campo sobre las actitudes de los mapuches frente a su lengua materna", RLA 21 (1983): 23-34.

Durán, Teresa y Ramos, Nelly. "Incorporación del español por los mapuches del centro-sur de Chile durante los siglos XVI, XVII y XVIII”, Lenguas Modernas 13 (1986): 17-36.

."Incorporación del español por los mapuches del centro sur de Chile durante el siglo XIX”, Lenguas Modernas 14 (1987): 179-196. 
“Castellanización formal en la Araucanía a través de la escuela", Lenguas Modernas 15 (1988): 131-154.

."Interacción mapudungun-castellano vinculada a contextos educacionales en una población rural", Lenguas Modernas 16 (1989): 97-114.

Esquit, Edgard. "Narrativas históricas estatistas o Guatemala como país heterogéneo en el pasado y en el presente", Itsmo. Revista virtual de estudios literarios y culturales centroamericanos 25-26 (2013): 2-24.

Fanon Frantz. "Racismo y cultura". En Por la Revolución Africana, editado por F. Fanon. México: Fondo de Cultura Económica, (1965): 38-52.

. Piel negra, máscaras blancas. Buenos Aires: Abraxas. 1973[1952].

Giménez, Gilberto. "Territorio y cultura”, Estudios sobre las Culturas contemporáneas 4 (1996): 9 -30 .

Ghio, Elsa. y Fernández, María Delia. Lingüística sistémico funcional. Aplicaciones a la lengua española. Santa Fe: Universidad Nacional del Litoral - Wadhuter Editores. 2008.

González, Pablo. "El colonialismo interno". En Sociología de la explotación, editado por P. González. Buenos Aires: CLACSO, (2006 [1969]): 185 - 205.

Gundermann, Hans, Canihuan, Jaqueline, Clavería, Alejandro y Faúndez, César. "El mapuzugun, una lengua en retroceso". Revista Atenea 503 (2011): 111-131.

Hernández, Arturo y Ramos, Nelly. "Situación sociolingüística de una familia mapuche. Proyecciones para abordar el problema de la enseñanza del castellano", RLA 21 (1983): 35-44.

Lagos, Cristian. "El Mapudungun en Santiago de Chile: vitalidad y representaciones sociales en los mapuche urbanos", Revista de Lingüística Teórica y Aplicada 50 (2012):161-184.

Lagos, Cristian y Espinoza, Marco, 2013. "La Planificación lingüística de la lengua mapuche en Chile a través de su historia", Lenguas Modernas, 42(2013): 47- 66.

Marimán, Pablo, Caniuqueo, Sergio, Millalen, José. y Levil, Rodrigo. ; ...Escucha winka ...! Cuatro ensayos sobre de historia nacional mapuche y un epílogo sobre el futuro. Santiago: LOM Ediciones. 2006.

Memmi, Albert. Retrato del colonizado. Precedido por el retrato del colonizador. Buenos Aires: Ediciones de la flor. 2001 [1966].

Millalén, José. Lof Mapu Mañiuko comuna de Galvarino, Región de la Araucanía: Un intento por escribir su historia a través de relatos orales. Tesis para optar al grado de Licenciado en Educación. Temuco: Universidad de La Frontera, 2005.

Moesbach, Wilhem. Vida y costumbres de los indígenas araucanos en la segunda mitad del siglo XIX. Santiago de Chile: Cervantes. 1930. Idioma mapuche. Temuco: San Francisco. 1962.

Nahuelpán, Héctor. "Formación colonial del estado y desposesión en Ngulumapu”. En Ta iñ fijke xipa rakizuameluwun. Historia, colonialismo y resistencia desde el país Mapuche. Editado por Comunidad de Historia Mapuche. Temuco: Ediciones Comunidad de Historia Mapuche, (2012): $123-156$.

.'Las 'zonas grises' de las historias mapuche. Colonialismo internalizado, marginalidad y políticas de la memoria”, Revista de Historia Social y de las Mentalidades 17 (2013): 9-31. 
Nahuelpan, Héctor y Antimil, Jaime. "Colonialismo republicano, violencia y subordinación racial mapuche en Chile durante el siglo XX", HiSTOReLo. Revista de Historia Regional y Local, 11(21) (2019): 211-247. https://dx.doi.org/10.15446/historelo.v11n21.71500.

."Mapuchezugun Ka Mapuche Kimün: Confronting Colonization in Chile (Nineteenth and Twentieth Centuries)". En McKinley, Elizabeth \& Tuhiwai, Linda, Handbook of Indigenous Education. Springer: Singapur, (2018):1-21 DOI/URL: https://doi.org/10.1007/978-981-10-18398_24-1.

Olate, Aldo. "Y después, lo estaban mirando a la rana. La competencia lingüístico-comunicativa del castellano en escolares de una comunidad bilingüe mapuche-castellano". Tesis para optar al grado de Doctor en Lingüística. Universidad de Concepción. 2012.

.Contacto lingüístico mapuzugun/castellano. Aspectos históricos, sociales y lingüísticos. Revisión bibliográfica y propuesta de análisis desde la dimensión morfosintáctica y tipológica”, Onomázein 36 (2017a): 122-158. Universidad Católica de Chile.

."Más allá del estado de vida de las lenguas... Elementos para el diagnóstico sociolingüístico de la dinámica interactiva del contacto mapuzugun /castellano", ALPHA 45 (2017b): 255-272. Universidad de los Lagos.

Olate, Aldo, Alonqueo, Paula y Caniguan, Jaqueline. "Interactividad lingüística castellano/mapudungun de una comunidad rural bilingüe", ALPHA 37 (2013): 265-284.

Olate, Aldo; Cisternas, César; Wittig, Fernando y Flores, Jaime. Los misioneros capuchinos bávaros y sus ideologías linguísticas sobre la lengua mapuche, Nueva Revista del Pacífico 67 (2017): 130156. Universidad de Playa Ancha.

Pinto, Jorge. La formación del Estado y la nación, y el Pueblo Mapuche. De la Inclusión a la Exclusión. Santiago: Ediciones DIBAM. 2003 [2001].

Quintriqueo, Segundo. Implicancias de un modelo curricular monocultural en contexto mapuche. Temuco: Universidad Católica. 2010.

Richards, Patricia. Racismo. El modelo chileno y el multiculturalismo neoliberal bajo la Concertación 1990-2010. Santiago: Pehuén. 2016.

Rivera, Silvia. Violencias (re)encubiertas en Bolivia. La Paz: Editorial Piedra Rota. 2012 [2010].

Rojas, Darío. "Actitudes e ideologías de hispanohablantes en torno a las lenguas indígenas en el Chile del siglo XIX”, Lenguas Modernas, 42 (2013): 85-98.

Salas, Adalberto. El mapuche o araucano. Santiago de Chile: Centro Estudios Públicos. 2006.

Scott, J. Los dominados y el arte de la Resistencia. México: Ediciones Era. 2004 [2000].

Stavenhagen, Rodolfo. "Clases, colonialismo y aculturación. Ensayo sobre un sistema de relaciones interétnicas en Mesoamérica", Cuadernos del Seminario de Integración Social Guatemalteca 19 (1968. [1963]): 7-63.

Stuchlik, Milan. Rasgos de la sociedad mapuche contemporánea. Santiago: Ediciones Nueva Universidad. 1974.

194.

."Las políticas indígenas en Chile y las imágenes de los mapuches”, CUHSO (1985): 159-

Thomason, Sara y Kaufman, Terence. Language contact, creolization, and genetic linguistics. Los Ángeles: University of California Press. 1988.

Wittig, Fernando. "Desplazamiento y vigencia del mapudungun en Chile: Un análisis desde el discurso reflexivo de los hablantes urbanos", Revista de Lingüística Teórica y Aplicada 47(2009): 135-155. 
Artículo. Jaime Antimil Caniupán, Aldo Olate Vinet. "El escenario actual de la lengua mapuche en un territorio.

Estudio de caso desde la historia y la sociolingüística"

."Adquisición y transmisión del Mapudungun en hablantes urbanos", Literatura y Lingüística 23(2011):193-211.

Wittig, Fernando y Farías Israel. “Trayectorias sociolingüísticas intergeneracionales. Una categoría para el análisis de procesos de transmisión y desplazamiento del mapuzugun", Atenea 517 (I) (2018): 123-138.

Zúñiga, Fernando. "Mapudunguwelaymi am? ¿Acaso ya no hablas mapudungun? Acerca del estado actual de la lengua mapuche”, Estudios Públicos 105 (2007).

Zúñiga, Fernando y Aldo Olate. "El estado de la lengua mapuche, diez años después. En Aninat, I. González, R. y Figueroa (Editores) El pueblo mapuche en el siglo XXI. Propuestas para un nuevo entendimiento entre culturas en Chile. Santiago: Centro de Estudios Públicos. 2017.

\section{Anexo.}

\section{Cuestionario sociolingüístico.}

"Ámbitos de uso y literacidad de la relación entre el castellano y el mapudungun"

Identificación

\begin{tabular}{|l|l|}
\hline Nombre & \\
\hline Sexo & \\
\hline Edad & \\
\hline Lugar de residencia & \\
\hline Nombre de la comunidad a la que pertenece & \\
\hline Actividad laboral & \\
\hline Nivel de estudios & S-E/ BAS/ MED/ SUP COMPL/ SUP INCL \\
\hline Estado civil & \\
\hline Número de hijos (si los tiene) & \\
\hline Personas con las que vive & \\
\hline
\end{tabular}

Instrucciones: este cuestionario se divide en dos partes. La primera parte trata preguntas de conocimiento general que se relacionan con el habla de la comunidad. La segunda, aborda actividades vinculadas con la lectura y la escritura.

Es necesario que se aplique idealmente con el entrevistador para tomar otros tipos de notas.

Solicitamos a usted que lea atentamente las preguntas y que responda de acuerdo a sus conocimientos y experiencias. Marque con una $X$ las alternativas que estime convenientes. Agradecemos su valiosa colaboración.

\section{PRIMERA PARTE. EL HABLA DE LA COMUNIDAD}

1. ¿Usted es mapuche?

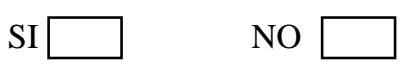

2. ¿Qué idioma habló primero?

3. ¿Usted habla cotidianamente mapudungun?

\begin{tabular}{|l|l|l|}
\hline SÍ, casi siempre & A veces & NO, casi nunca \\
\hline & & \\
\hline
\end{tabular}

4. ¿Se considera un buen hablante de mapudungun?

\begin{tabular}{|l|l|l|}
\hline SÍ & Más o menos & NO \\
\hline & & \\
\hline
\end{tabular}


Por qué:

5. ¿En su comunidad se habla cotidianamente el mapudungun?

\begin{tabular}{|l|l|l|}
\hline Sí, casi siempre & A veces & NO, casi nunca \\
\hline & & \\
\hline
\end{tabular}

6. ¿En su comunidad, conoce personas que no hablan castellano?

$\mathrm{Rp}$

7. ¿En su comunidad, hay personas que ya no hablan mapudungun?

$\mathrm{Rp}$

8. ¿Con qué frecuencia habla usted mapudungun en los "lugares" que se mencionan a continuación?

\begin{tabular}{|l|l|l|l|}
\hline Eventos & Casi siempre & A veces & Casi nunca \\
\hline Machitún & & & \\
\hline Ngillatun & & & \\
\hline Siembra/cosecha & & & \\
\hline Palin & & & \\
\hline Velorio & & & \\
\hline Reuniones comunidad & & & \\
\hline Fiestas familiares & & & \\
\hline Actos escolares & & & \\
\hline Reuniones de apoderados & & & \\
\hline
\end{tabular}

9. ¿Con quiénes y con qué frecuencia habla mapudungun?

\begin{tabular}{|l|l|l|l|}
\hline & Casi siempre & A veces & Casi nunca \\
\hline Padres & & & \\
\hline Esposa & & & \\
\hline Hijos & & & \\
\hline Parientes & & & \\
\hline Amigos & & & \\
\hline Abuelos & & & \\
\hline
\end{tabular}

10. ¿Quiénes, en la comunidad, hablan mapudungun actualmente y con qué frecuencia?

\begin{tabular}{|l|l|l|l|}
\hline & Casi siempre & A veces & Casi nunca \\
\hline Ancianos & & & \\
\hline Adultos & & & \\
\hline Jóvenes & & & \\
\hline Niños & & & \\
\hline & & & \\
\hline
\end{tabular}

11. ¿Entre quiénes y con qué frecuencia se habla mapudungun en la comunidad?

\begin{tabular}{|l|l|l|l|}
\hline & Casi siempre & A veces & Casi nunca \\
\hline Ancianos & & & \\
\hline Adultos & & & \\
\hline Jóvenes & & & \\
\hline Niños & & & \\
\hline Niños y adultos & & & \\
\hline Niños y ancianos & & & \\
\hline Adultos y ancianos & & & \\
\hline Jóvenes y ancianos & & & \\
\hline Jóvenes y adultos & & & \\
\hline
\end{tabular}

12. ¿De qué se habla en mapudungun y con qué frecuencia? 


\begin{tabular}{|l|l|l|l|}
\hline & Casi siempre & A veces & Casi nunca \\
\hline Noticias & & & \\
\hline Política & & & \\
\hline Temas de cultura & & & \\
\hline Historias & & & \\
\hline Actividades cotidianas & & & \\
\hline Trabajo & & & \\
\hline Negocios & & & \\
\hline Religión & & & \\
\hline Problemas personales & & & \\
\hline
\end{tabular}

13. ¿Dónde se habla el mapudungun dentro de la comunidad? Marque las tres alternativas donde más se practique.

\begin{tabular}{|l|l|l|l|l|l|}
\hline CASA & CAMINO & & MICRO & \\
\hline TRABAJO & & IGLESIA & & FIESTA & \\
\hline ESCUELA & & & & & \\
\hline
\end{tabular}

14. ¿En estos lugares se habla castellano también?

\begin{tabular}{|l|l|l|l|}
\hline & Casi siempre & A veces & Casi nunca \\
\hline Casa & & & \\
\hline Trabajo & & & \\
\hline Escuela & & & \\
\hline Camino & & & \\
\hline Iglesia & & & \\
\hline Micro & & & \\
\hline Fiesta & & \\
\hline
\end{tabular}

15. ¿Qué se habla más hoy en la comunidad?

\section{CASTELLANO \\ MAPUDUNGUN}

16. ¿Con qué frecuencia (dentro de la comunidad) se habla castellano en los "lugares" que se mencionan a continuación?

\begin{tabular}{|l|l|l|l|}
\hline Lugares & Casi siempre & A veces & Casi Nunca \\
\hline Machitún & & & \\
\hline Ngillatun & & & \\
\hline Siembra/cosecha & & & \\
\hline Palin & & & \\
\hline Velorio & & & \\
\hline Reuniones comunidad & & & \\
\hline Fiestas familiares & & & \\
\hline Actos escolares & & & \\
\hline Reuniones de apoderados & & & \\
\hline
\end{tabular}

17. ¿De qué se habla en castellano y con qué frecuencia?

\begin{tabular}{|l|l|l|l|}
\hline Temas & Casi siempre & A veces & Casi Nunca \\
\hline Noticias & & & \\
\hline Política & & & \\
\hline Temas de cultura & & & \\
\hline Historias & & & \\
\hline Actividades cotidianas & & & \\
\hline Trabajo & & & \\
\hline Negocios & & & \\
\hline
\end{tabular}




\begin{tabular}{|l|l|l|l|}
\hline Religión & & & \\
\hline Problemas personales & & & \\
\hline
\end{tabular}

18. ¿Ha escuchado algún epew en castellano?

\begin{tabular}{|l|l|l|l|}
\hline SI & & NO & \\
\hline
\end{tabular}

¿Cuentan todavía epew en mapudungun?

\begin{tabular}{|l|l|l|l|}
\hline SI & & NO & \\
\hline
\end{tabular}

19. ¿Ha escuchado algún ngutram en castellano?

\begin{tabular}{|l|l|l|l|}
\hline SI & & NO & \\
\hline
\end{tabular}

¿Todavía hacen ngutram en mapudungun?

\begin{tabular}{|l|l|l|l|}
\hline SI & & NO & \\
\hline
\end{tabular}

20. ¿Ha escuchado ngulam en castellano?

\begin{tabular}{|l|l|l|l|}
\hline SI & & NO & \\
\hline
\end{tabular}

¿Siguen realizando ngulam en mapudungun?

\begin{tabular}{|l|l|l|l|}
\hline SI & & NO & \\
\hline
\end{tabular}

21. Cuando usted les habla a sus hijos, ¿en qué lengua les habla?

En castellano

En mapudungun

¿Qué siente usted ante eso?

¿Por qué cree que pasa eso?

21.b. ¿Ellos en qué idioma le responden?

En castellano

En mapudungun

¿Qué siente usted ante eso?

¿Por qué cree que pasa eso?

22. ¿En la escuela qué se habla más?

Castellano $\square$ Mapudungun

23. Según su juicio ¿Los niños de la comunidad hablan bien castellano?

\begin{tabular}{|l|l|l|}
\hline Sí, la mayoría & Solo algunos & No, Unos pocos \\
\hline & & \\
\hline
\end{tabular}

Por qué:

24. Según su juicio ¿Los adultos de la comunidad hablan bien castellano?

\begin{tabular}{|l|l|l|}
\hline Sí, la mayoría & Solo algunos & No, Unos pocos \\
\hline & & \\
\hline
\end{tabular}

Por qué:

25. ¿De los niños que viven en la comunidad cuántos cree usted que hablan solo mapudungun?

\begin{tabular}{|l|l|l|l|}
\hline La mayoría & Algunos & Unos pocos & Ninguno \\
\hline & & & \\
\hline
\end{tabular}

26. ¿De los niños que viven en la comunidad, cuántos cree usted que hablan solo castellano?

\begin{tabular}{|l|l|l|l|}
\hline La mayoría & Algunos & Unos pocos & Ninguno \\
\hline & & & \\
\hline
\end{tabular}

27. De los niños que viven en la comunidad, ¿cuántos cree usted que hablan mezclado? 


\begin{tabular}{|l|l|l|}
\hline La mayoría & Algunos & Unos pocos \\
\hline & & \\
\hline
\end{tabular}

\section{SEGUNDA PARTE: HABLAR Y LEER.}

1. ¿Tiene libros?

\begin{tabular}{|l|l|l|l|}
\hline Muchos & Algunos & Unos pocos & Ninguno \\
\hline & & & \\
\hline
\end{tabular}

2. ¿Cuándo fue la última vez que compró libros o revistas?

\begin{tabular}{|l|l|}
\hline Hace unos días & \\
\hline Hace unas semanas & \\
\hline Hace unos meses & \\
\hline Hace mucho tiempo & \\
\hline
\end{tabular}

3. ¿Usted lee en castellano?

\begin{tabular}{|l|l|l|}
\hline Sí, generalmente & A veces, ocasionalmente & No, rara vez \\
\hline & & \\
\hline
\end{tabular}

4. ¿Usted lee en mapudungun?

\begin{tabular}{|l|l|l|}
\hline Sí, generalmente & A veces, ocasionalmente & No, rara vez \\
\hline & & \\
\hline
\end{tabular}

5. ¿Escribe en castellano?

\begin{tabular}{|l|l|l|}
\hline Sí, generalmente & A veces, ocasionalmente & No, rara vez \\
\hline & & \\
\hline
\end{tabular}

6. ¿Escribe en mapudungun?

\begin{tabular}{|l|l|l|}
\hline Sí, generalmente & A veces, ocasionalmente & No, rara vez \\
\hline & & \\
\hline
\end{tabular}

7. ¿Ha escrito cuentos o poesías en mapuche o castellano?

\begin{tabular}{|l|l|l|}
\hline Sí, generalmente & A veces, ocasionalmente & No, rara vez \\
\hline & & \\
\hline
\end{tabular}

8. ¿En la comunidad hay gente que lea o escriba con frecuencia?

\begin{tabular}{|l|l|l|l|}
\hline Muchos & Algunos & Unos pocos & Ninguno \\
\hline & & & \\
\hline
\end{tabular}

9. Frente al siguiente listado de actividades nombre las cuatro que más le gustan

\begin{tabular}{|l|l|}
\hline ACTIVIDADES & \\
\hline Ver televisión & \\
\hline Contar epew & \\
\hline Trabajar la tierra & \\
\hline Escuchar historias de gente mayor & \\
\hline Leer cuentos & \\
\hline Escuchar la naturaleza & \\
\hline Escuchar un epew & \\
\hline
\end{tabular}




\begin{tabular}{|l|l|}
\hline Ir a pescar & \\
\hline Sembrar/cosechar & \\
\hline Enseñar a estudiar/estudiar alguna materia & \\
\hline Escribir relatos & \\
\hline Hablar mapudungun & \\
\hline Hacer negocios & \\
\hline Cocinar & \\
\hline Escuchar radio & \\
\hline Ir de compras al pueblo & \\
\hline Otra & \\
\hline
\end{tabular}

10. ¿Usa cuadernos para anotar sus actividades?

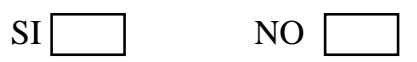

11. ¿Qué prefiere? (elija dos)

Leer un epew

Escuchar un epew
Narrar un epew

Escribir un epew

12. ¿Con qué frecuencia sus hijos deben leer por tareas escolares?

\begin{tabular}{|l|l|l|l|}
\hline Cotidianamente & Una vez por semana & De vez en cuando durante el mes & Casi nunca \\
\hline & & & \\
\hline
\end{tabular}

13. ¿Con qué frecuencia sus hijos escriben tareas escolares?

\begin{tabular}{|l|l|l|l|}
\hline Cotidianamente & Una vez por semana & De vez en cuando durante el mes & Casi nunca \\
\hline & & & \\
\hline
\end{tabular}

14. ¿Con qué frecuencia sus hijos leen por placer?

\begin{tabular}{|l|l|l|l|}
\hline Cotidianamente & Una vez por semana & De vez en cuando durante el mes & Casi nunca \\
\hline & & & \\
\hline
\end{tabular}

15. ¿Con qué frecuencia sus hijos escriben por placer?

\begin{tabular}{|l|l|l|l|}
\hline Cotidianamente & Una vez por semana & De vez en cuando durante el mes & Casi nunca \\
\hline & & & \\
\hline
\end{tabular}

16. ¿Qué quiere que sea su hijo en el futuro?

17. ¿Para qué sirve la escuela?

18. ¿A qué edad aprendió a leer y escribir?

19. ¿Para qué sirve leer?

20. ¿Para qué sirve escribir?

¿Quiere hacer algún otro comentario relacionado con el tema del cuestionario? 